\title{
Effect of Acidosis on Contractile Function in the Newborn Rabbit Heart
}

\author{
TOSHIO NAKANISHI, HIROFUMI OKUDA, MAKOTO NAKAZAWA, AND ATSUYOSHI TAKAO \\ Department of Pediatric Cardiology, Heart Institute of Japan, Tokyo Women's Medical College, Tokyo, Japan
}

\begin{abstract}
Effects of respiratory and metabolic acidosis (pH approximately 6.8) on myocardial function were studied in the newborn and adult rabbits. Mechanical function was studied in the isolated arterially perfused heart preparation. Acidosis was induced either by increase of the perfusate $\mathrm{PCO}_{2}$ or by decrease of the bicarbonate content. During respiratory acidosis, developed tension (DT) decreased to $43 \pm 3 \%$ of control $(n=18)$ in the adult and this depression was significantly greater than in the newborn (DT $=92 \pm 4 \%, n=6)$. Depression of DT by respiratory acidosis was observed even at high extracellular Ca. During metabolic acidosis, mechanical function decreased gradually and DT at $\mathbf{3 0}$ min into acidosis in the adult was $78 \pm 3 \%$ of control $(n=6)$. This depression of DT in the adult was significantly greater than in the newborn (DT at $30 \mathrm{~min}=96 \pm 1 \%$ of control, $n=6$ ). Statistical analysis using paired $t$ test showed that respiratory acidosis, but not metabolic acidosis, caused significant negative inotropism in the newborn. Myofibrils were isolated and the ATPase was measured at $10^{-8}$ to $10^{-4} \mathrm{M}$ $\mathrm{Ca}$ and at $\mathrm{pH}$ of 7.1 (control), 6.5, and 6.0. Reducing $\mathrm{pH}$ depressed the ATPase activity similarly in the newborn and adult. Intracellular buffer capacity was determined by titrating muscle homogenate with $\mathrm{HCl}$. Although the initial pH was not different, addition of $\mathrm{HCl}$ to the homogenate caused less decrease in $\mathrm{pH}$ in the newborn. These data indicate that contractile function in the newborn heart is more resistant to acidosis and this may be due partly to the greater intracellular buffer capacity. (Pediatr Res 19: 482-488, 1985)
\end{abstract}

\section{Abbreviations}

DT, developed tension

$\mathrm{RT}$, resting tension

$+\mathrm{dT} / \mathrm{dt}$ max, maximal rate of tension development

DTT, dithiothreitol

TES, N-tris[hydroxymethyl]methyl-2-aminoethanesulfonic acid

Several investigators examined the effect of acidosis on cardiac function in the premature animals $(1,2)$. These in vivo studies showed that respiratory acidosis, but not metabolic acidosis, depressed cardiac function. Because preload, afterload, and heart

Received November 8, 1984; accepted January 18, 1985.

Address for reprint requests Dr. Toshio Nakanishi, Pediatric Cardiology, Heart Institute of Japan, Tokyo Women's Medical College, 10 Kawada-cho, Shinjuku, Tokyo, Japan.

Supported by Research Grants 59480241 and 59570411 from the Japanese Ministry of Education, Science, and Culture and grant-in-aid from Japan Research Promotion Society for Cardiovascular Diseases. rate change with development, it is difficult to assess the agerelated difference in the effect of acidosis per se in the in vivo study. Developmental changes in the effect of acidosis have not been studied in the isolated heart preparation.

Myocardial contractile force is largely dependent on the myofibrillar ATPase activity and the amount of contractile calcium (3). Kentish and Nayler (4) showed in the adult rabbit that acidosis reduced myofibrillar ATPase activity and increased calcium concentration which was required to activate ATPase to the half-maximal value. Age-related changes in the $\mathrm{pH}$ dependence of the myofibrillar ATPase have not been studied. Furthermore, competitive interaction between hydrogen $\left(\mathrm{H}^{+}\right)$and calcium $\left(\mathrm{Ca}^{2+}\right)$ on cardiac contraction has been reported by several investigators $(5,6)$. The relationship between $\mathrm{Ca}^{2+}$ and $\mathrm{H}^{+}$in the premature myocardium is not determined. Accordingly, the present study was designed to investigate developmental changes in 1) the effect of acidosis on contractile function, 2) $\mathrm{pH}$ dependence of myofibrillar ATPase, and 3) the interaction between $\mathrm{H}^{+}$ and $\mathrm{Ca}^{2+}$ on contractile function in the isolated heart preparation.

\section{METHODS}

The experiment utilized the fetus (28th day of gestation), newborn (2-5 day old), and adult (6-12 month old) New Zealand White rabbits. After sacrificing the doe with pentobarbital (50 $\mathrm{mg} / \mathrm{kg}$ ), the fetuses were delivered by cesarean section, placed on a warmed $\left(38^{\circ} \mathrm{C}\right)$ water-pad, and used within $2 \mathrm{~h}$ after delivery. The fetal, newborn, and adult rabbits were heparinized $(0.15 \mathrm{U} /$ $\mathrm{g}$ body weight $)$ and anesthetized with pentobarbital $(0.05 \mathrm{mg} / \mathrm{g}$ body weight, intravenous or intraperitoneal). The heart was then excised from the chest cavity and used for either mechanical function study or biochemical determination.

Experimental preparation. Experiments were performed in the isolated, arterially perfused ventricular (in the fetus and newborn) or septal (in the newborn and adult) preparation as described previously $(3,7-10)$. In the ventricular preparation, the aorta was cannulated with PE-50 polyethylene cannula and the heart was perfused with oxygenated perfusate at a constant perfusion rate of $2.5 \mathrm{ml} / \mathrm{g}$ tissue per minute using a Harvard pump. The base of the right and left ventricle was fixed between two Harmon forceps and the apex was attached to the Statham (UC3) transducer using a silk suture. In the septal preparation, the septal branch of the left coronary artery was cannulated and the right and left ventricular free walls were trimmed away. The base of the septum was suspended to a force transducer. The muscle was stimulated at $36 \mathrm{bpm}$, and its temperature was maintained at 27 $\pm 0.5^{\circ} \mathrm{C}$. The following parameters of mechanical function were monitored continuously: DT, RT, tension development $(+\mathrm{dT} /$ $\mathrm{dt}$ max), maximal rate of relaxation, time to peak tension, and half-time to relaxation.

Perfusion solutions. The control Krebs-Henseleit solution contained in $\mathrm{mM}: \mathrm{NaCl}, 118 ; \mathrm{KCl}, 6 ; \mathrm{CaCl}_{2}, 1.5$; glucose, $6 ; \mathrm{MgCl}_{2}$, 
1; $\mathrm{NaHCO}_{3}, 24$; and $\mathrm{NaH}_{2} \mathrm{PO}_{3}, 0.436$. The control solution was equilibrated with $95 \% \mathrm{O}_{2}$ and $5 \% \mathrm{CO}_{2}$ yielding a final $\mathrm{pH}$ of 7.35-7.42. Respiratory acidosis was produced by equilibration with $80 \% \mathrm{O}_{2}-20 \% \mathrm{CO}_{2}$ and the perfusate $\mathrm{pH}$ was $6.81 \pm 0.01$. Metabolic acidosis was produced by decreasing $\mathrm{NaHCO}_{3}$ to 6 $\mathrm{mM}$ (the solution gassed with $95 \% \mathrm{O}_{2}-5 \% \mathrm{CO}_{2}$ ) and $\mathrm{pH}$ of the perfusate was $6.78 \pm 0.02$. In the metabolic acidosis solution, $\mathrm{NaHCO}_{3}$ was replaced with $\mathrm{NaCl}$ and the total $\mathrm{Na}^{+}$concentration was kept to $142.436 \mathrm{mM}$.

Experimental protocol. Initially, the muscles were perfused with a control solution containing $1.5 \mathrm{mM}$ calcium for $60 \mathrm{~min}$ to allow for stabilization of mechanical function. During the initial 40 min of each experiment, the length of the muscle preparation was adjusted so that the tension was equal to $90 \%$ of maximal tension. After this initial period, both resting tension and length-tension relationship remained unchanged under control conditions. The following studies were then performed.

1) Effect of respiratory or metabolic acidosis at $1.5 \mathrm{mM}[\mathrm{Ca}]_{0}$ : the muscles were perfused with an acidotic solution (either respiratory or metabolic) for 10 or $30 \mathrm{~min}$ and then perfused with a control solution for $30 \mathrm{~min}$.

2) Mechanical function during respiratory acidosis at various $[\mathrm{Ca}]_{0}$ : the muscles were perfused with either a control solution or an acidotic solution containing $1.5 \mathrm{mM}[\mathrm{Ca}]_{0}$ for $20 \mathrm{~min}$. After the mechanical function reached a new steady state, the muscles were perfused with solutions containing $0.1,0.3,0.75$, $1.5,3,7.5,15$, and $30 \mathrm{mM} \mathrm{Ca}^{2+}$ (pH kept either at 7.4 or 6.8 ). The duration of perfusion was $5 \mathrm{~min}$ at each calcium concentration. Mechanical function reached a new steady state 2 min after switching to a new calcium concentration, and all measurements were made at $4 \mathrm{~min}$. Parameters describing mechanical function were expressed as a percentage of control values and a $\mathrm{g} / \mathrm{g}$ tissue wet weight.

Titration of muscle homogenate. After the heart was excised from the thoracic cavity, the heart was washed in a ice-cold saline. Approximately $1 \mathrm{~g}$ of the muscles were then suspended in $11 \mathrm{vol}$ of Tris buffer ( $1 \mathrm{mM}, \mathrm{pH} 7.1)$ containing $150 \mathrm{mM} \mathrm{KCl}$ and $1 \mathrm{mM}$ EDTA, which was equilibrated with $100 \% \mathrm{O}_{2}$. The muscles were homogenized with a Polytron tissue processor (Brinkman, Westbury, NY) at a setting of 4.6 for $4 \mathrm{~s}$. The $\mathrm{pH}$ of the homogenate was monitored using a $\mathrm{pH}$ electrode, a $\mathrm{pH}$ meter, and a recorder (Toa-dempa, Tokyo, Japan). The flasks containing the homogenate were gassed with $100 \% \mathrm{O}_{2}$. The homogenate was stirred slowly and was titrated using $1 \mathrm{~N} \mathrm{HCl}$. The titration was carried out at $27^{\circ} \mathrm{C}$ and all procedures were finished within $5 \mathrm{~min}$ after homogenization. In some experiments, the heart was excised from the animal, perfused via the aorta with the homogenizing solution (approximately $10 \mathrm{ml} / \mathrm{g}$ muscle), and then homogenized. This perfusion procedure, however, did not affect the titration curve significantly, suggesting the negligible buffer capacity of the blood and extracellular fluid existed in the muscle at the time of the homogenization.

Myofibrillar isolation. The myofibrillar fraction was isolated by a modified method of Solaro et al. (11) as described previously (3). The muscle was homogenized in $10 \mathrm{vol}$ of a solution containing $60 \mathrm{mM} \mathrm{KCl}, 10 \mathrm{mM}$ TES (pH 7.1), and $1 \mathrm{mM}$ DTT and centrifuged at $750 \times g$ for $15 \mathrm{~min}$. The pellet was washed four times with the same solution. The resulting pellet was suspended in a solution containing $60 \mathrm{mM} \mathrm{KCl}, 10 \mathrm{mM}$ TES, $1 \mathrm{mM}$ DTT, and $1 \%$ Triton $\mathrm{X}-100(\mathrm{pH} 7.1)$ and centrifuged. The resulting pellet was suspended in a solution containing $60 \mathrm{mM} \mathrm{KCl}, 10$ mM TES, 1 mM DTT, and 2 mM EGTA (pH 7.1) and then washed four times with the initial solution. The final pellet was suspended in a solution containing $50 \mathrm{mM} \mathrm{KCl}, 1 \mathrm{mM}$ TES, and $1 \mathrm{mM}$ DTT (pH 7.1).

Protein was measured by the Lowry method (12) using bovine serum albumin as a standard.

Assay of $\mathrm{Ca}^{2+}$-ATPase activity. Myofibrillar ATPase activity

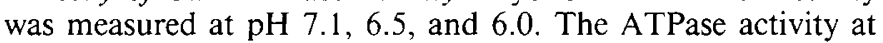
$\mathrm{pH} 7.1$ was considered to be a control value since several studies suggest that intracellular $\mathrm{pH}$ under physiological conditions is about 7.1 (13).

The ATPase activity was measured as described previously at $27^{\circ} \mathrm{C}$ and at low ionic strength $(0.0758 \mathrm{M})$ using a modified method of Solaro et al. (11). A desired Ca concentration in the medium was obtained using an EGTA-buffer system (3). The absolute binding constants used in the present study are similar to those cited by Fabiato and Fabiato (13) and these values were adjusted for the ionic strength. The apparent binding constants at various $\mathrm{pH}$ were calculated using these absolute binding constants and these values are shown in Table 1. Using these apparent binding constants, the composition of the reaction mixture was obtained from the calculation and programs described by Fabiato and Fabiato (13). The reaction medium contained $30 \mathrm{mM}$ TES, $1 \mathrm{mM} \mathrm{K}$-EGTA, $5 \mathrm{mM}$ azide, and various amounts of $\mathrm{CaCl}_{2}, \mathrm{Na}_{2}-\mathrm{ATP}, \mathrm{MgCl}_{2}$, and $\mathrm{KCl}$. The $\mathrm{pH}$ was adjusted with $1 \mathrm{M} \mathrm{KOH}$. Concentrations of free $\mathrm{Mg}(3.16$ $\mathrm{mM})$, Mg-ATP (3.16 mM), total Na $(6.5 \mathrm{mM})$, and total $\mathrm{K}(54$ $\mathrm{mM}$ ) in the media remained virtually constant. The final volume of the media was $1 \mathrm{ml}$. The reaction was started by the addition of enzymes (150 $\mathrm{g}$ of myofibrillar protein) and stopped by the addition of $0.5 \mathrm{ml}$ of ice-cold $20 \%$ trichloroacetic acid. Inorganic phosphate concentration in the medium was then measured using the method of Fiske and SubbaRow (27). Ca-activated myofibrillar ATPase was calculated as myofibrillar ATPase at various pCa-basal ATPase (no $\mathrm{Ca}$ added).

Statistical analysis. Results were expressed as the mean $\pm \mathrm{SE}$. Statistical analysis was performed using the two-tailed $t$ test (14). Paired $t$ test was used to determine the significance of the inotropic effect of acidosis. The probability was considered to be significant if the $p$ value was less than 0.05 .

\section{RESULTS}

Mechanical function. Mechanical function parameters in the fetus, newborn, and adult under control conditions were similar to the previously reported values (3) except that in the present study DT in the adult (Fig. 3) was slightly less than the previous data.

Respiratory acidosis. Respiratory acidosis caused a rapid decline in DT and $+\mathrm{dT} / \mathrm{dt}(\max )$, followed by a partial recovery of these variables (Fig. 1). Mechanical function reached a steady state after $10 \mathrm{~min}$ into acidosis and in a preliminary study it remained stable for at least $60 \mathrm{~min}$ into acidosis. Since the responses of DT and $+\mathrm{dT} / \mathrm{dt}(\max )$ to acidosis were similar, only the DT data will be presented. The effect of acidosis in the newborn ventricular preparation was not significantly different from that in the newborn septal preparation. The newborn data shown below are those obtained in the ventricular preparation. In the newborn, DT decreased to $65 \pm 5 \%$ of control at $3 \mathrm{~min}$ and recovered to $92 \pm 4 \%$ at 10 min into acidosis $(n=6)$ (Fig. 2). Statistical analysis using paired $t$ test showed that DT at 10 min was significantly less than control in both the newborn and adult. The negative inotropism of acidosis in the adult was greater than in the newborn (Fig. 2). Upon returning to a control solution, an overshoot of DT and $+\mathrm{dT} / \mathrm{dt}(\max )$ was observed and there was no age-related difference in the extent of this overshoot. In the fetus, acidosis depressed DT to $68 \pm 2 \%$ at 3 $\min$ and to $89 \pm 2 \%$ at $10 \mathrm{~min}(n=6)$ and these values were

Table 1. Apparent stability constants at various $\mathrm{pH}$

\begin{tabular}{lllll}
\hline & & \multicolumn{3}{c}{ Stability constants } \\
\cline { 3 - 5 } Ligand & Metal & \multicolumn{1}{c}{$\mathrm{pH} 7.1$} & \multicolumn{1}{c}{$\mathrm{pH} 6.5$} & $\mathrm{pH} 6.0$ \\
\hline EGTA & $\mathrm{Ca}$ & $4.166 \times 10^{6}$ & $2.670 \times 10^{5}$ & $2.698 \times 10^{4}$ \\
EGTA & $\mathrm{Mg}$ & $5.582 \times 10$ & $1.137 \times 10$ & 3.400 \\
ATP & $\mathrm{Ca}$ & $4.934 \times 10^{3}$ & $2.056 \times 10^{3}$ & $7.942 \times 10^{2}$ \\
ATP & $\mathrm{Mg}$ & $2.133 \times 10^{4}$ & $9.048 \times 10^{3}$ & $3.666 \times 10^{3}$ \\
ATP & $\mathrm{K}$ & 4.377 & 2.086 & 1.079 \\
ATP & $\mathrm{Na}$ & 6.475 & 5.002 & 4.332 \\
\hline
\end{tabular}


Newborn
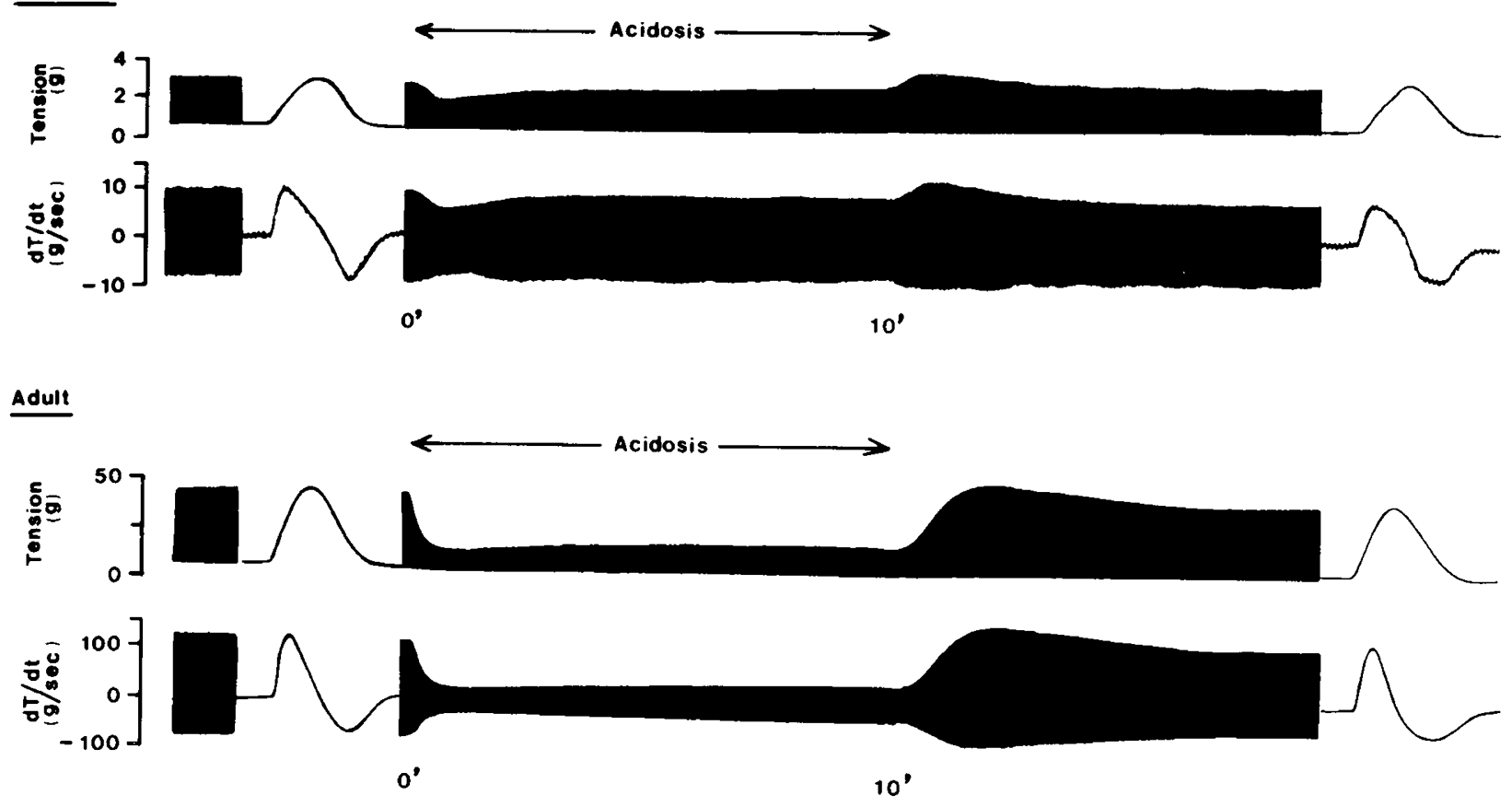

Fig. 1. Typical experiments that show the effect of respiratory acidosis ( $\mathrm{pH}$ 6.8) on tension and first derivatives of tension development (dT/dt). In the newborn and adult, respiratory acidosis caused a rapid decline of mechanical function, followed by a partial recovery.

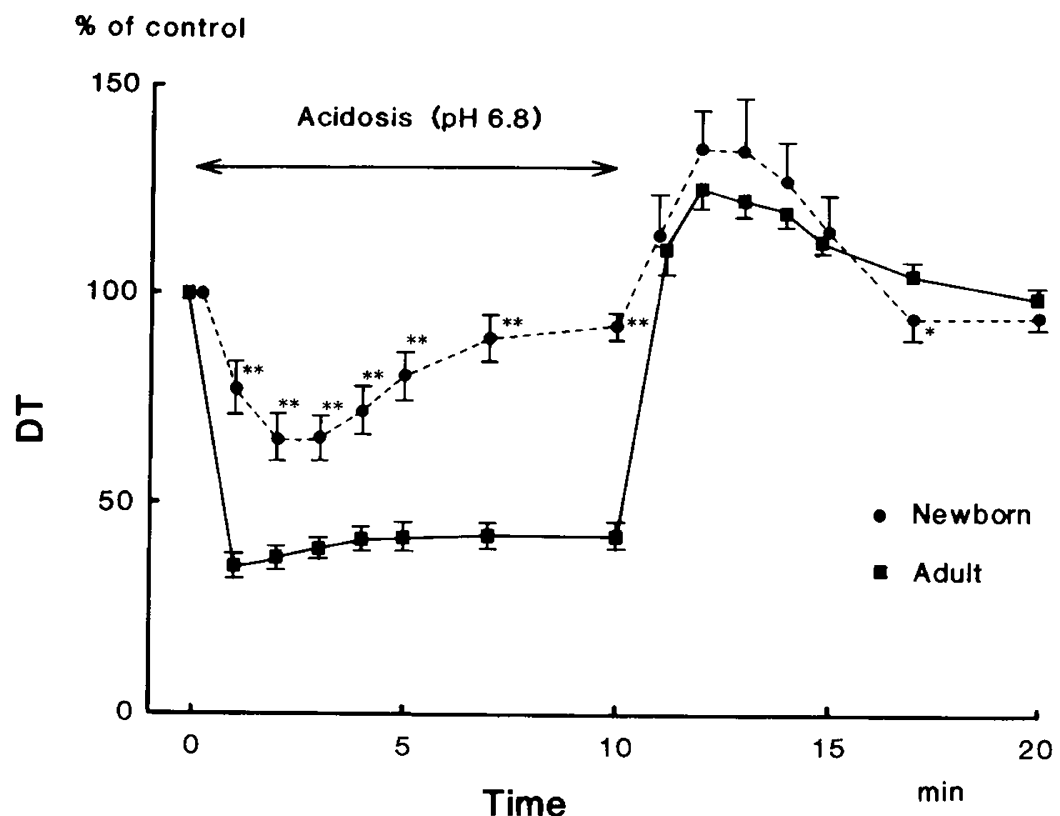

Fig. 2. Effect of respiratory acidosis on DT. In the adult, the negative inotropic effect of acidosis was significantly greater than in the newborn. ${ }^{*} p<0.05,{ }^{* *} p<0.01$ (significant difference from the adult value).

not significantly different from those in the newborn and therefore only the newborn heart was utilized as a premature myocardium in the following experiments.

Figure 3 shows DT at various $[\mathrm{Ca}]_{0}$ in the control and acidotic muscles. In the newborn, the responses of DT to various [Ca] were similar in the control and acidotic muscles. A double reciprocal plot of DT as a function of $[\mathrm{Ca}]_{0}$ showed that the $\mathrm{Km}$ value at $\mathrm{pH} 7.4(2.6 \pm 0.2 \mathrm{mM} \mathrm{Ca})$ was not significantly different from the value at $\mathrm{pH} 6.8(3.2 \pm 0.4 \mathrm{mM})$. In the adult, acidosis depressed DT at all $[\mathrm{Ca}]_{0}$ studied. In the adult, the $\mathrm{Km}$ value at pH $7.4(1.3 \pm 0.1 \mathrm{mM})$ was significantly $(p<0.05)$ different from that at $\mathrm{pH} 6.8(4.1 \pm 0.8 \mathrm{mM})$. Thus, acidosis shifted the dose (Ca)-response (DT) curve to the right and downward in the adult, suggesting a noncompetitive inhibition between hydrogen and calcium ions. Figure 3 also shows that DT at high [Ca $]_{0}$ (and at $\mathrm{pH}$ 7.4) in the adult was similar to that in the newborn. This was due to slightly depressed DT in the adult compared to the previously reported value (3). In the present study, however, $+\mathrm{dT} / \mathrm{dt}(\max )$ at high $[\mathrm{Ca}]_{0}$ was similar to the previous value (3) and the maximal $+\mathrm{dT} / \mathrm{dt}(\max )$ in the adult was significantly greater than that in the newborn.

In both control and acidotic adult muscles, increases in RT were observed at high [Ca]o (Fig. 4). In the newborn, RT did not change from control at high [Ca $]_{0}$ as described previously (3).

Metabolic acidosis. Metabolic acidosis initially caused minimal increases and then gradual decreases in DT and $+\mathrm{dT} /$ $\mathrm{dt}(\max )$ (Fig. 5). In the newborn, DT at 30 min into acidosis was $96 \pm 1 \%$ of control $(n=6)$. This value was not significantly 

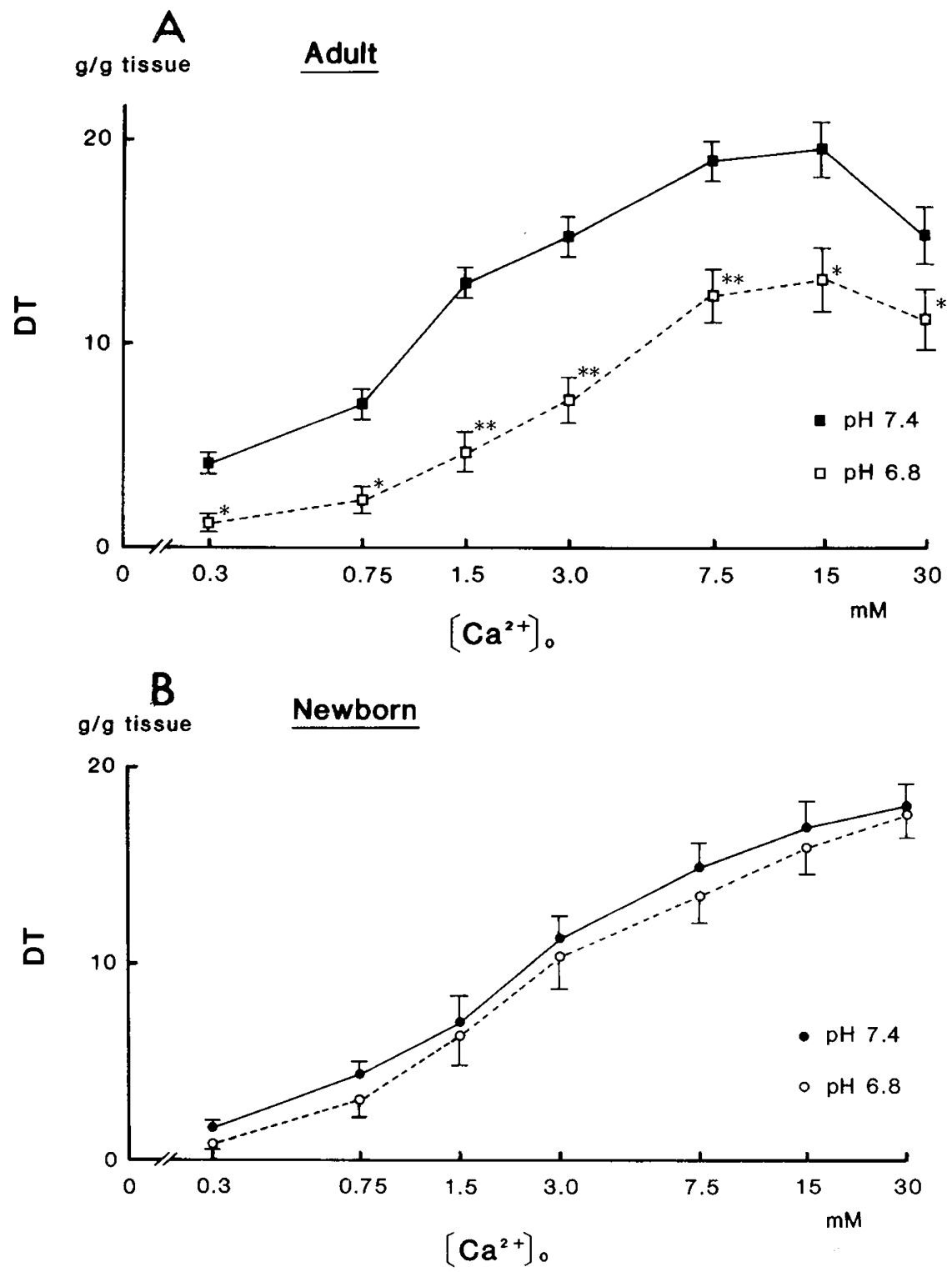

Fig. 3. Effect of $[\mathrm{Ca}]_{0}$ on the DT in the control and acidotic (respiratory) muscles in the adult $(A)$ and newborn $(B) .{ }^{*} p<0.05,{ }^{* *} p<0.01$ (significant difference from the value at $\mathrm{pH}$ 7.4).

different from control and was significantly greater than that in the adult ( $80 \pm 3 \%$ of control, $n=6)$. On returning to the control solution, DT and $+\mathrm{dT} / \mathrm{dt}(\max )$ decreased further and then returned to the control level in both age groups. If the mechanical function at new steady states during acidosis (the values at 30 min in metabolic acidosis and at $10 \mathrm{~min}$ in respiratory acidosis) are compared, the depressant effect of metabolic acidosis was significantly less than that of respiratory acidosis in the adult (but not in the newborn).

Titration of the muscle homogenate. Although the initial $\mathrm{pH}$ of the homogenate was not significantly different, addition of $\mathrm{HCl}$ to the homogenate caused significant difference in $\mathrm{pH}$ between the newborn and adult (Fig. 6). Figure 6 also shows that the buffer capacity of the homogenizing solution per se is very weak.

Myofibrillar ATPase. At pH 7.1, myofibrillar ATPase activity in the adult was greater than that in the newborn as reported previously (3). Reducing the media pH depressed myofibrillar ATPase activity similarly in the newborn and adult (Fig. 7). At pCa 5, myofibrillar ATPase at $\mathrm{pH} 6.8$ was $74 \pm 6 \%$ of control (pH 7.1) in the newborn and $73 \pm 6 \%$ in the adult. At $\mathrm{pH} 6.0$ (and at pCa 5), myofibrillar ATPase activity was $56 \pm 3 \%$ of control in the newborn and $55 \pm 5 \%$ of control in the adult. It must be noted that at $\mathrm{pCa}$ range greater than 5 the relative depression of the Ca-activated ATPase by acidosis is greater than at $\mathrm{pCa} 5$ in both age groups.

\section{DISCUSSION}

The present study was designed to determine the effect of acidosis on contractile function in the isolated heart of the premature rabbit. The negative inotropism of acidosis in the fetus and newborn was less than in the adult (Fig. 2). In the present study, the control value of DT in the adult was slightly less than the previously reported data (3) and as a result DT in the adult at high $[\mathrm{Ca}]_{0}$ was similar to that in the newborn (Fig. 3). However, $+\mathrm{dT} / \mathrm{dt}(\max )$ was identical to the previous data (3) and the maximal $+\mathrm{dT} / \mathrm{dt}(\max )$ at high $[\mathrm{Ca}]_{0}$ in the adult was significantly greater than in the newborn. The reasons for this discrepancy between DT and $+\mathrm{dT} / \mathrm{dt}(\max )$ are not clear. Since myocardial ATP contents under control conditions and during acidosis were not depressed (data not shown), it is unlikely that oxygenation of the adult muscle was inadequate. It must be noted that the effect of acidosis on DT and $+\mathrm{dT} / \mathrm{dt}(\max )$ were 


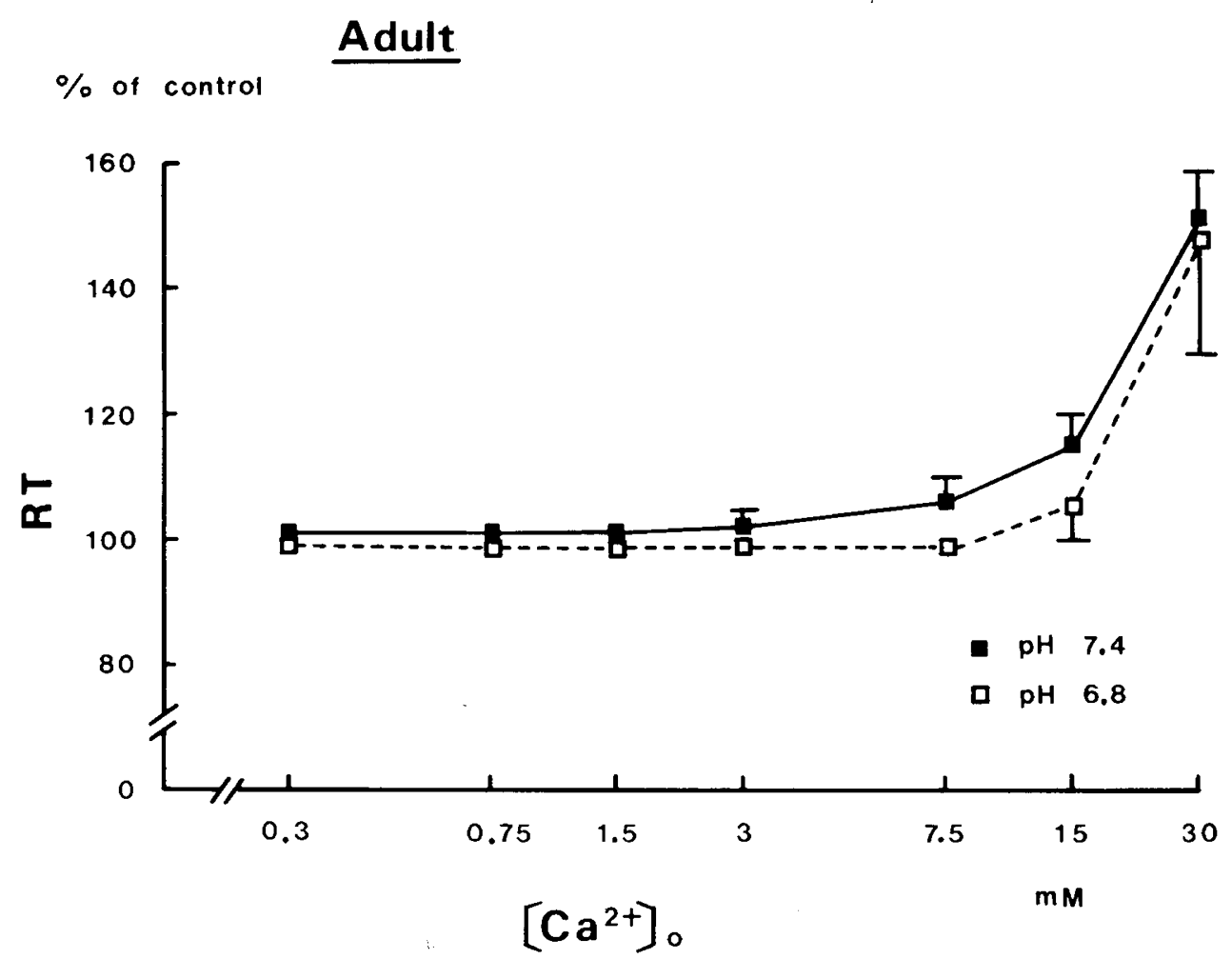

Fig. 4. Effect of $[\mathrm{Ca}]_{0}$ on RT in the control and respiratory acidotic muscles. In the adult, RT increased at $30 \mathrm{mM}[\mathrm{Ca}]_{0}$ significantly $(p<0.05)$ both at $\mathrm{pH} 7.4$ and 6.8 .

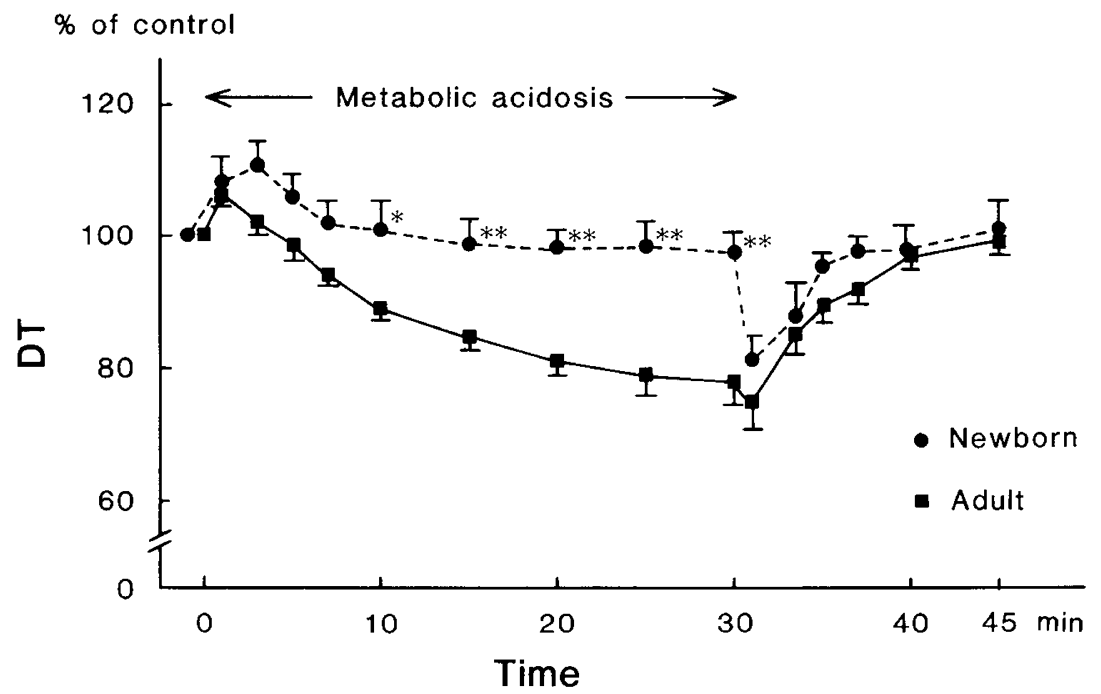

Fig. 5. Effect of metabolic acidosis (pH 6.8) on DT. Metabolic acidosis caused a transient increase in DT, followed by a gradual decrease. On returning to the control solution, DT decreased further and then recovered to the control level. ${ }^{*} p<0.05,{ }^{* *} p<0.01$ (significant difference from the adult value).

similar and for these reasons it is likely that the present data (Fig. 2 ) indeed show the greater resistance of the premature myocardium to acidosis.

In both the newborn and adult, respiratory acidosis caused a more rapid and greater decline than metabolic acidosis. Similar results regarding the difference between respiratory and metabolic acidosis have been described previously (6, 15-17). Ellis and Thomas (18) showed that during acidosis intracellular $\mathrm{pH}$ changed in a similar manner to mechanical function. This suggests that intracellular, rather than extracellular, $\mathrm{pH}$ is a controlling factor of the inotropism. Ellis and Thomas (18) also showed a transient increase in intracellular $\mathrm{pH}$ during metabolic acidosis and this may explain the transient increase in mechanical function observed in the present study (Fig. 4). The fact that the negative inotropism of metabolic acidosis in the newborn was minimal may be in agreement with the results of Downing et al. (1) obtained in the lamb. However, the duration of acidosis was relatively short in the present study and it remains possible that a longer period of metabolic acidosis may depress contractility significantly.

Myocardial contractile force is largely dependent on the amount of myofibrils, myofibrillar ATPase, and the amount of calcium reaching myofibrils. Although the precise mechanisms for the negative inotropism of acidosis are not clear, decreases in myofibrillar ATPase activity and the amount of contractile calcium have been postulated $(4,5,6,19,20)$. The age-related difference in the negative inotropism of acidosis might be due to the differences in 1) intracellular $\mathrm{pH}$ during acidosis or 2) the 

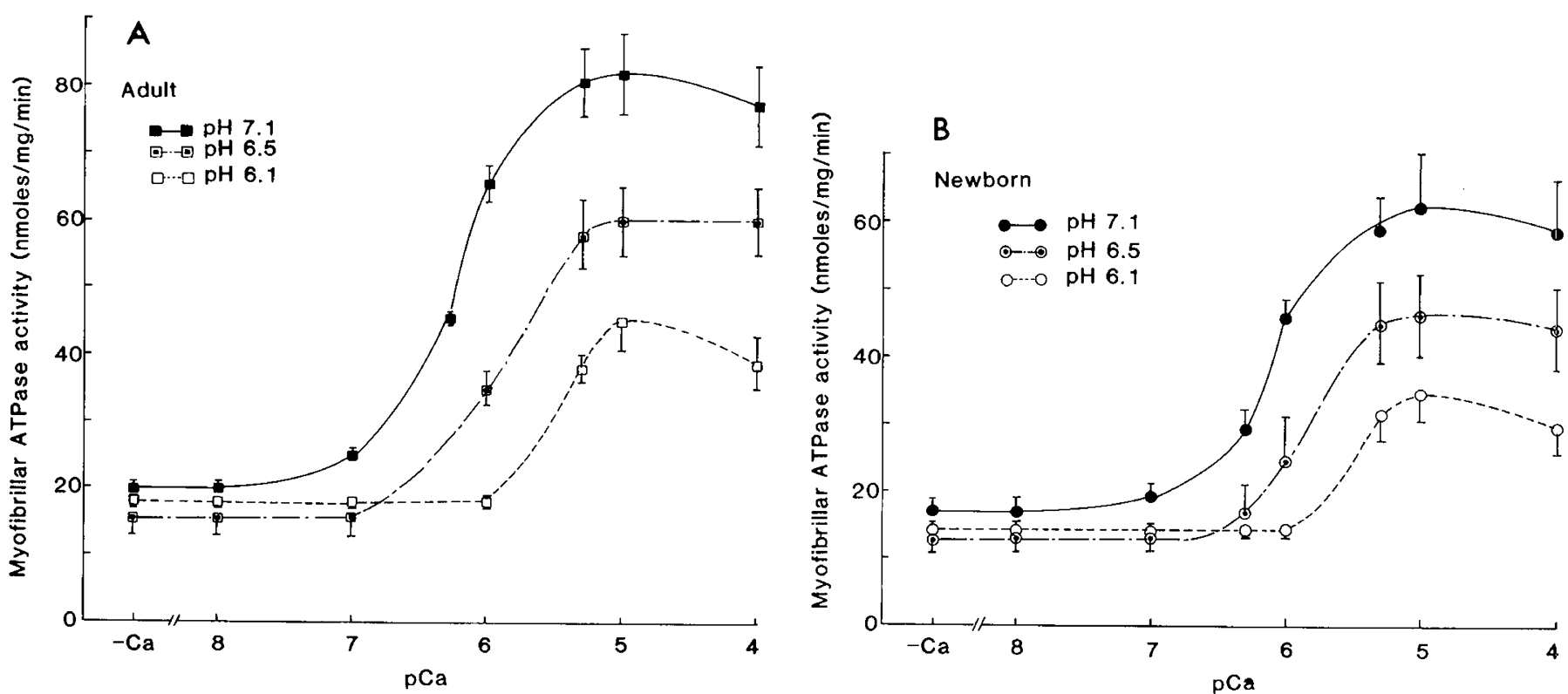

Fig. 6. Myofibrillar ATPase at various pH in the adult $(A)$ and newborn $(B)$. The relative depression of the ATPase at low pH was similar in the two age groups.

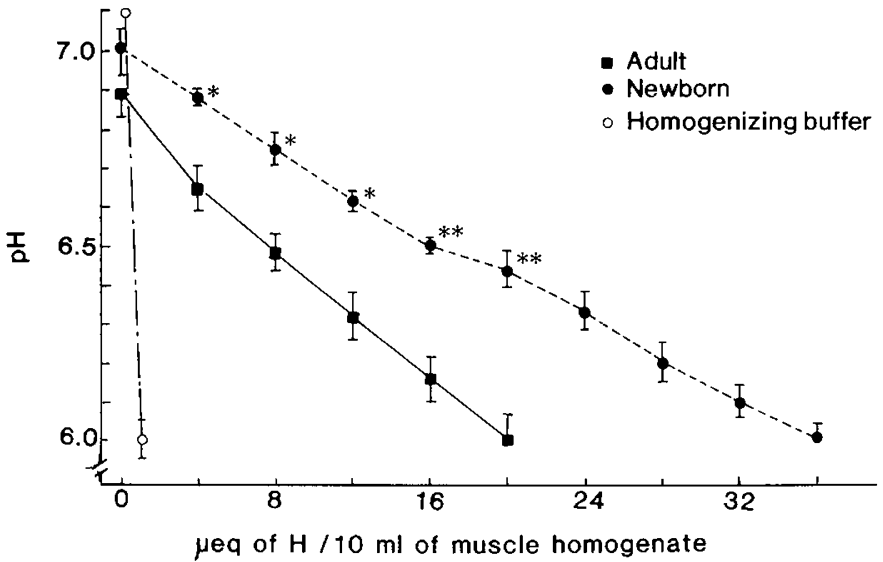

Fig. 7. Titration curve of the muscle homogenate. Although the initial $\mathrm{pH}$ was not different, addition of $\mathrm{HCl}$ caused significant difference $\left({ }^{*} p\right.$ $<0.05,{ }^{* *} p<0.01$ ) in the $\mathrm{pH}$ of the homogenate between the two age groups.

effect of acidosis per se on myofibrillar ATPase and/or the amount of contractile calcium. Kentish and Nayler (4) showed in the adult rabbit that acidosis reduced myofibrillar ATPase activity and increased $\mathrm{Ca}$ concentration required to reach half maximal ATPase activity. The present finding in the adult was similar to the result of Kentish and Nayler (4). Furthermore, the relative depression of myofibrillar ATPase was similar in the newborn and adult. Therefore, it is difficult to explain the agerelated difference in the effect of acidosis by the myofibrillar ATPase.

One may argue that $\mathrm{H}^{+}$may decrease $\mathrm{Ca}$ binding to troponin (5) and this effect in the newborn may be different from that in the adult. However, since myofibrillar ATPase represents Caactivated myosin ATPase in the presence of actin, troponin, and tropomyosin, age-related difference in the competition of hydrogen and calcium ions at the troponin-binding site is unlikely.

Williamson et al. (6) showed that the decreased contractile function during acidosis was restored by raising $[\mathrm{Ca}]_{0}$ and postulated a competitive interaction between $\mathrm{H}^{+}$and $\mathrm{Ca}^{2+}$ on the regulatory sites of myocardial contractility. In contrast, Mattiazzi et al. (19) showed that the negative inotropic effect of acidosis could not be completely offset by increasing $[\mathrm{Ca}]_{0}$. The present finding in the adult (Fig. 3) is in agreement with the Mattiazzi's data. Furthermore, increases in resting tension were observed at high $[\mathrm{Ca}]_{0}$ in both control and acidotic muscles. Jarmakani et al. (21) showed that myocardial contracture was caused by increased cytosolic $\mathrm{Ca}$ and/or decreased myocardial high energy phosphates. Because no decrease in myocardial ATP content was observed at high $[\mathrm{Ca}]_{0}$ (data not shown), it is likely that myofibrils were saturated with $\mathrm{Ca}^{2+}$.

The hypothesis that contractile force decreases during acidosis in the presence of enough calcium is also supported by the study of Allen and Orchard (22). These authors showed that on induction of acidosis aequorin light emission (an intracellular $\mathrm{Ca}$ indicator) did not change initially and it increased gradually with a similar time course to that of the recovery of mechanical function. Furthermore, Fabiato and Fabiato (23) and Donaldson and Hermansen (24) have shown in skinned cardiac fibers that the maximal tension decreased during acidosis at saturating $\mathrm{Ca}$ concentrations. Therefore, the age-related difference in the effect of acidosis might not be explained by the difference in the amount of contractile calcium. Of course, it is possible that acidosis depresses functions of intracellular organelles such as sarcoplasmic reticulum (25), mitochondria, and sarcolemma (26) and these effects may alter cellular Ca metabolism. Fabiato and Fabiato (23) suggested that acidosis might depress Ca loading and release from sarcoplasmic reticulum. Since contraction of the premature myocardium may be less dependent on Ca-release from sarcoplasmic reticulum (3), developmental changes in the function of this organelle may explain the difference in the effect of acidosis. Although the relationships between dysfunction of the intracellular organelles and negative inotropism are not clear, the effect of acidosis on the intracellular organelles in the premature myocardium remains to be studied.

Since the age-related difference in the negative inotropism of acidosis might be due to the difference in the intracellular $\mathrm{pH}$, intracellular buffer capacity was estimated by titrating muscle homogenate. The present results show that buffer capacity of the homogenate in the newborn was greater than in the adult (Fig. 6). This method, however, does not estimate intracellular buffering capacity under physiological conditions and therefore has some limitations. First, oxygenation of the muscle homogenate might not be adequate during the titration procedure. In a preliminary study, however, $\mathrm{pH}$ of the homogenate remained stable for at least $10 \mathrm{~min}$ both in the newborn and adult, suggesting that oxygenation was enough at least in this period. Second, intracellular organelles might not remain intact after homogenization procedure. Although this possibility remains, 
the homogenization procedure in the present study was similar to that used previously to isolate sarcoplasmic reticulum and mitochondria (3). These data suggest that intracellular buffer capacity in the newborn muscle is greater than in the adult and this, at least in part, may explain the age-related difference in the inotropic effect of acidosis. The reasons for the difference in buffer capacity are unknown. In addition to the electrolytes and proteins, intracellular organelles may play important roles as buffers $(6,16,18)$. In order to determine the age-related difference in the intracellular buffer capacity under more physiological conditions, direct measurement of intracellular $\mathrm{pH}$ should be performed.

In summary, the present study showed that the negative inotropic effect of acidosis in the developing heart is less than in the adult and this may be due in part to the greater intracellular buffer capacity.

\section{REFERENCES}

1. Downing SE, Talner NS, Gardner TH 1965 Cardiovascular responses to metabolic acidosis. Am J Physiol 208:237-242

2. Fisher DJ 1983 Acidemia depresses cardiac contractility and output in newborn lambs. Circulation 68(suppl III): 122

3. Nakanishi T, Jarmakani JM 1984 Developmental changes in myocardial mechanical function and subcellular organelles. Am J Physiol 246:H615625

4. Kentish JC, Nayler WG 1979 The influence of pH on the Ca-regulated ATPase of cardiac and white skeletal myofibrils. J Mol Cell Cardiol 11:611-617

5. Katz AM, Hecht HH 1969 The early pump failure of the ischemic heart. Am J Med 47:497

6. Williamson JR, Safer B, Rich T, Schaffer S, Kobayashi K 1975 Effects of acidosis on myocardial contractility and metabolism. Acta Med Scand Suppl 587:95-111

7. Nakanishi T, Jarmakani JM 1981 Effect of extracellular sodium on mechanical function in the newborn rabbit. Dev Pharmacol Ther 2:188-200

8. Nakanishi T, Jarmakani JM 1981 The effect acetyl strophanthidin on myocardial function and potassium and calcium exchange in the newborn rabbit. Am J Physiol 241:H637-645

9. Nakanishi T, Nishioka K, Jarmakani JM 1982 The mechanism of the tissue
Ca gain during reoxygenation after hypoxia in the rabbit myocardium. Am J Physiol 242:H437-449

10. Nakanishi T, Shimizu T, Uemura S, Jarmakani JM 1984 Ouabain effect on myocardial mechanical function and sodium pump in the fetus. Am $\mathbf{J}$ Physiol 246:H213-H221

11. Solaro RJ, Pang DC, Briggs FN 1971 The purification of cardiac myofibrils with Triton X-100. Biochim Biophys Acta 245:259-262

12. Lowry OH, Rosebrough NJ, Farr AL, Randall RJ 1951 Protein measurements in the Folin phenol reagents. J Biol Chem 193:265-275

13. Fabiato A, Fabiato F 1979 Calculator programs for computing the composition of the solutions containing multiple metals and ligands used for experiments in skinned muscle cells. J Physiol (Paris) 75:463-505

14. Snedecor GW, Cochran WG 1967 Statistical Methods. Iowa State University Press, Ames, IA

15. Mattiazzi AR, Cingolani HE 1977 Biphasic effect of hypercapnia on myocardial contractility. Arch Int Physiol Biochim 85:11-25

16. Poole-Wilson PA, Langer GA 1975 Effect of $\mathrm{pH}$ on ionic exchange and function in rat and rabbit myocardium. Am J Physiol 229:570-581

17. Serur JR, Skeleton CL, Bodem R, Sonnenblick EH 1976 Respiratory acid-base changes and myocardial contractility. J Mol Cell Cardiol 8:823-836

18. Ellis D, Thomas RC 1976 Direct measurement of the intracellular pH of mammalian cardiac muscle. J Physiol 262:755-771

19. Mattiazzi AR, Cingolani HE, Castuma ES 1979 Relationship between calcium and hydrogen ions in heart muscle. Am J Physiol 237:H497-503

20. Poole-Wilson PA, Langer GA 1979 Effect of acidosis on mechanical function and Ca exchange in rabbit myocardium. Am J Physiol 236:H525-533

21. Jarmakani JM, Nagatomo T, Langer GA 1978 The effect calcium and high energy phosphate compounds on myocardial contracture in the newborn and adult rabbit. J Mol Cell Cardiol 10:1017-1029

22. Allen DG, Orchard CH 1984 Measurement of intracellular calcium concentration in heart muscle. J Mol Cell Cardiol 16:117-128

23. Fabiato A, Fabiato $\mathrm{F} 1978$ Effects of $\mathrm{pH}$ on the myofilaments and the sarcoplasmic reticulum of skinned cells from cardiac and skeletal muscles. J Physiol 276:233-255

24. Donaldson SB, Hermansen L 1978 Differential, direct effects of $\mathrm{H}$ and Caactivated force of skinned fiber from soleus, cardiac, and abductor magnus muscles of rabbits. Pflugers Arch 376:55-65

25. Nakamura Y, Schwart A 1972 The influence of hydrogen ion concentration on calcium binding and release by skeletal muscle sarcoplasmic reticulum. $\mathbf{J}$ Genet Physiol 59:22

26. Philipson KD, Bersohn MM, Nishimoto AY 1982 Effects of pH on $\mathrm{Na}-\mathrm{Ca}$ exchange in canine cardiac sarcolemmal vesicles. Circ Res 50:287-293

27. Fiske CH, SubbaRow Y 1925 The colorimetric determination of phosphorus. J Biol Chem 66:375-400 